Michael Roesyanto, Rezi Erdiansyah: Perngaruh Hubungan Self-Disclosure dan Kepribadian Extraversion terhadap Keterampilan Komunikasi Interpersonal Young Worker di Jakarta

\title{
Pengaruh Hubungan Self-Disclosure dan Kepribadian Extraversion terhadap Keterampilan Komunikasi Interpersonal Young Worker di Jakarta
}

\author{
Michael Roesyanto, Rezi Erdiansyah \\ michaelroesyanto@gmail.com,rezie@fikom.untar.ac.id \\ Fakultas Ilmu Komunikasi Universitas Tarumanagara
}

\begin{abstract}
This study was to determine the effect of self-disclosure and extraversion personality on the interpersonal communication skills of young workers in Jakarta. The approach used by researchers in this study is a quantitative approach which is then followed by a correlational method and the researcher also distributes questionnaires to 150 respondents spread across the Jakarta area. Data analysis used SPSS version 24 software. The researcher found that there was a significant influence between self-disclosure and extraversion personality on the interpersonal communication skills of young workers in Jakarta. From the two dependent variables, it turns out that the extraversion personality variable has a greater influence than self-disclosure on the communication skills of young workers. Thus, it can be concluded that interpersonal communication is influenced by self-disclosure and extraversion personality.
\end{abstract}

Keywords: extraversion personality, interpersonal communication, self-disclosure

\begin{abstract}
Abstrak
Penelitian ini untuk mengetahui pengaruh self-disclosure dan kepribadian extraversion terhadap keterampilan komunikasi interpersonal young worker di Jakarta. Pendekatan yang digunakan oleh peneliti dalam penelitian ini adalah pendekatan kuantitatif yang kemudian diikuti oleh metode korelasional dan peneliti juga melakukan penyebaran kuisioner pada 150 responden yang tersebar di wilayah Jakarta. Analisis data menggunakan software SPSS versi 24. Peneliti menemukan adanya pengaruh antara self-disclosure dan kepribadian extraversion terhadap keterampilan komunikasi interpersonal young worker di Jakarta yang cukup signifikan. Dari kedua variabel dependen ternyata variabel kepribadian extraversion memiliki pengaruh yang lebih besar dibandingkan self-disclosure terhadap keterampilan komunikasi young worker. Dengan demikian dapat disimpulkan bahwa komunikasi interpersonal dipengaruhi oleh self-disclosure dan kepribadian extraversion.
\end{abstract}

Kata Kunci: kepribadian extraversion, komunikasi interpersonal, self-disclosure

\section{Pendahuluan}

Makhluk sosial merupakan sebutan yang sering digunakan untuk menggambarkan makhuk hidup yaitu manusia. Hal ini dikarenakan bahwa manusia akan membutuhkan orang lain dan tidak dapat hidup sendiri. Oleh karena itu, manusia tidak luput dari interaksi dan yang terpenting adalah komunikasi. Pada saat ini individu yang memiliki kemampuan berkomunikasi yang baik menjadi daya tarik tersendiri bagi dirinya maupun orang lain. Dengan mempunyai kemampuan berkomunikasi yang baik dapat membangun relasi dan juga mendapatkan hasil yang positif. 
Komunikasi antara dua orang atau lebih dinamakan komunikasi interpersonal. Menurut Mulyana (2011), komunikasi interpersonal adalah proses penyampaian informasi baik secara verbal maupun nonverbal yang dilakukan antara dua invidu atau lebih secara langsung. Dalam melakukan proses komunikasi interpersonal tentunya individu akan melihat topik pembicaraan yang akan dibicarakan. Tidak semua orang dapat membuka diri dalam berkomunikasi, hal ini dinamakan selfdisclosure atau keterbukaan diri. Self-disclosure upaya individu untuk memberikan informasi mengenai dirinya kepada orang lain atau sebaliknya (Bungin, dalam Zulfa, 2019)

Selain self-disclosure, tipe-tipe kepribadian juga sangat mempengaruhi seseorang dalam berkomunikasi. Kepribadian Big Five (Friedman \& Schustack, dalam Siregar 2019) dibagi menjadi: Openness, Conscientiousness, Extraversion, Agreeableness, Neuroticism yang kemudian disingkat menjadi OCEAN. Ryckman (2004) berpendapat bahwa setiap dimensi dari kepribadian Big Five mempunyai poin positif dan poin negatif. Terutama kepribadian E yang memiliki rasa percaya diri, sangat aktif, cerewet, memiliki rasa optimis yang tinggi, serta menyukai kesenangan dan selalu terlihat ceria secara alami

Pada penelitian ini peneliti ingin meneliti mengenai self-disclosure atau keterbukaan diri dan kepribadian extraversion yang dimiliki young worker. Young Worker adalah individu yang berada di antara usia 15-24 tahun atau di bawah 25 tahun.

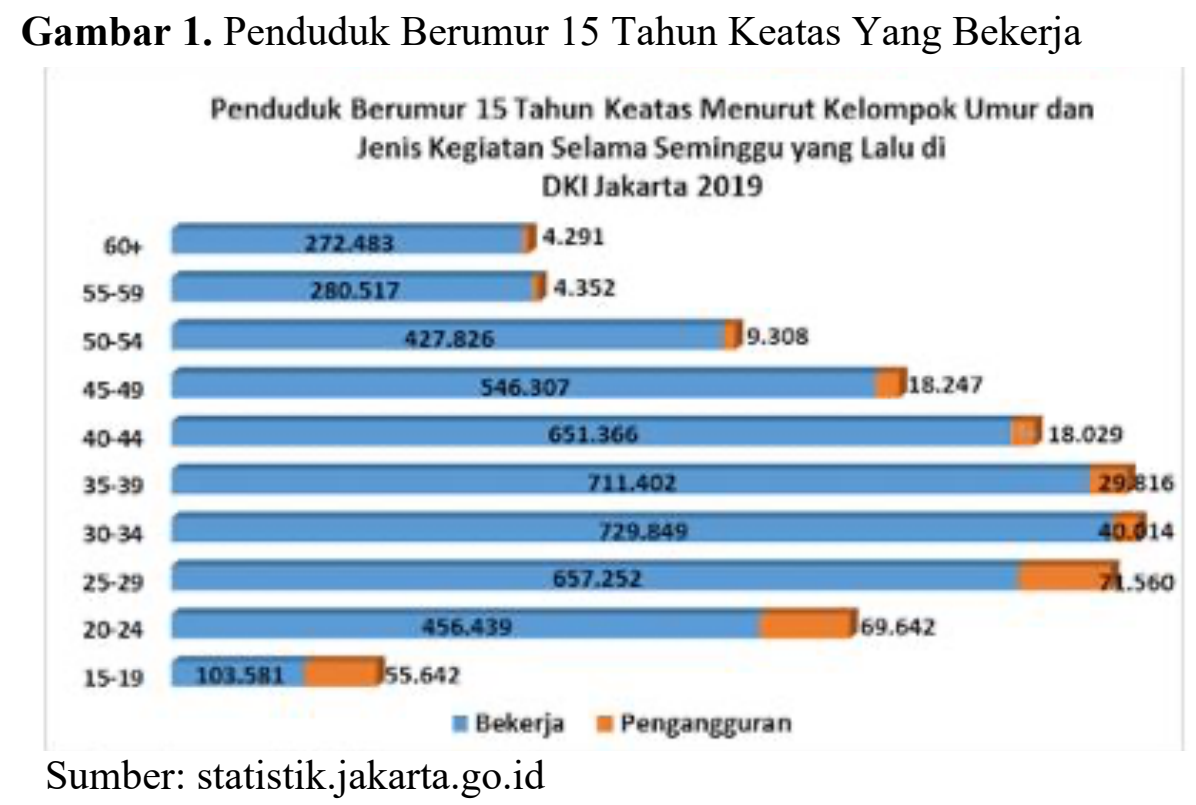

Berdasarkan data pada statistik diatas dapat disimpulkan bahwa pekerja muda atau young worker yang berusia dibawah 25 tahun lebih mendominasi "sedang bekerja" dibandingan yang "tidak sedang bekerja" atau "pengangguran".

\section{Metode Penelitian}

Pendekatan yang digunakan dalam penelitian ini adalah pendekatan kuantitatif. Pendekatan ini merupakan penelitian yang berlandasakan pada filsafat positivism. Dalam penelitian ini populasi atau sampel yang dipilih dengan acak serta pengumpulan data menggunakan instrumen, analisis data bersifat statistik (Sugiyono, 
Michael Roesyanto, Rezi Erdiansyah: Perngaruh Hubungan Self-Disclosure dan Kepribadian Extraversion terhadap Keterampilan Komunikasi Interpersonal Young Worker di Jakarta

dalam Juliana 2020). Faenkel dan Wallen (2008:328) mengatakan bahwa metode korelasional adalah suatu metode yang bertujuan untuk mengetahui hubungan dan tingkat hubungan antara dua variabel atau lebih tanpa ada upaya untuk mempengaruhi variabel tersebut sehingga variabel yang ada tidak termanipulasi. Maka dari itu, peneliti memilih metode korelasional sebagai metode penelitian guna untuk mengetahui hubungan serta tingkat hubungan antar variabel.

Cara yang digunakan dalam penelitian ini untuk memperoleh data yaitu dengan melakukan penyebaran kuisioner sebanyak 150 responden. Peneliti memilih menggunakan kuisioner karena sangat efisien dengan menjangkau populasi yang dipilih oleh peneliti yaitu daerah Jakarta. Peneliti menggunakan data entry dan data sekunder sebagai sumber data.

Menurut Sugiyono (2015), data primer adalah sumber data yang langsung memberikan data kepada pengumpul data. Data primer diperoleh dari penyebaran kuisioner kepada responden. Sedangkan data sekunder adalah data yang diperoleh atau dikumpulkan oleh orang yang melakukan penelitian dari sumber-sumber yang telah ada (Hasan, dalam Imaroh 2017:617). Data yang telah diperoleh yaitu dari studi pustaka, literatur, penelitian terdahulu, buku dan lain sebagainya.

Setelah pengumpulan data selesai dilakukan, peneliti mengolah serta menganalisis data. Peneliti menggunakan program SPSS versi 24 karena SPSS merupakan program aplikasi yang memiliki manajemen data lingkungan grafis dengan menggunakan menu-menu deskriptif dan kotak-kotak dialog yang sederhana serta memiliki kemampuan untuk analisis statistik cukup tinggi. Peneliti juga melakukan analisis dengan menggunakan Uji $\mathrm{T}$ untuk melihat seberapa besar pengaruh dari masing-masing variabel independen kepada variabel dependen.

\section{Hasil Temuan dan Diskusi}

Peneliti menyebarkan 150 kuisioner kepada Young Worker yang tersebar di Jakarta yang terdiri dari 79 orang yang berjenis kelamin laki-laki atau 52.7\% dan perempuan sebanyak 71 orang atau $47.3 \%$. Individu yang termasuk dalam kategori Young Worker merupakan individu yang berusia 18-24 tahun. Responden dengan umur 18 tahun dalam penelitian ini terdiri dari 1 orang atau $0.7 \%$, responden dengan usia 19 tahun terdiri dari 5 orang yang setara dengan 3.3\%, responden dengan umur 20 tahun terdiri dari 20 orang yang setara dengan $13.3 \%$, responden berusia 21 tahun terdiri dari 79 orang atau $52.7 \%$, responden berusia 22 tahun terdiri dari 34 orang atau $22.7 \%$, responden berusia 7 orang atau $4.7 \%$ dan responden berusia 24 tahun terdiri dari 4 orang atau $2.7 \%$.

Tabel 1. Analisis Koefisien Korelasi

\begin{tabular}{clrrr}
\hline & & $\begin{array}{c}\text { Self- } \\
\text { disclosure } \\
\left(\mathrm{X}_{1}\right)\end{array}$ & $\begin{array}{c}\text { Kepribadian } \\
\text { Extraversion } \\
\left(\mathrm{X}_{2}\right)\end{array}$ & $\begin{array}{c}\text { Keterampilan } \\
\text { Komunikasi } \\
\text { Interpersonal } \\
(\mathrm{Y})\end{array}$ \\
\hline Self- & Pearson Correlation & 1 & $.581^{* *}$ & $.500^{* *}$ \\
disclosure & Sig. (2-tailed) & & .000 & .000 \\
$\left(\mathrm{X}_{1}\right)$ & $\mathrm{N}$ & 150 & 150 & 150 \\
\hline Kepribadian & Pearson Correlation & $.581^{* *}$ & 1 & $.562^{* *}$ \\
Extraversion & Sig. (2-tailed) & .000 & & .000 \\
$\left(\mathrm{X}_{2}\right)$ & $\mathrm{N}$ & 150 & 150 & 150 \\
\hline & & & &
\end{tabular}




\begin{tabular}{clrrr}
\hline Keterampilan & Pearson Correlation & $.500^{* *}$ & $.562^{* *}$ & 1 \\
Komunikasi & Sig. (2-tailed) & .000 & .000 & \\
Interpersonal & $\mathrm{N}$ & 150 & 150 & 150 \\
(Y) & & & \\
\hline Sumber: Pengolahan Data SPSS & &
\end{tabular}

Melalui hasil analisis koefisien korelasi (R) di atas, didapatkan bahwa nilai signifikansi dari variabel self-disclosure (X1) terhadap Keterampilan Komunikasi Interpersonal sebesar 0,500 dan nilai signifikansi variabel Kepribadian Extraversion (X2) terhadap variabel Keterampilan Komunikasi Interpersonal sebesar 0,562. Sehingga peneliti menyiimpulkan bahwa variabel Self-disclosure (X1) dan variabel Kepribadian Extraversion (X2) berkorelasi terhadap Keterampilan Komunikasi Interpersonal.

Berdasarkan Tabel 1 dapat disimpulkan Self-disclosure dan Kepribadian Extraversion berhubungan secara positif terhadap Keterampilan Komunikasi Interpersonal dengan korelasi sedang $(0,41 \mathrm{~s} / \mathrm{d} 0,60)$.

Tabel 2. Uji Reliabilitas

\begin{tabular}{ccc}
\hline Variabel & Cronbach's Alpha & Keterangan \\
\hline Self-disclosure & 0,773 & Reliabel \\
\hline Kepribadian & 0,674 & Reliabel \\
Extraversion & & Reliabel \\
\hline $\begin{array}{c}\text { Keterampilan } \\
\text { Komunikasi }\end{array}$ & 0,820 & \\
Interpersonal & & \\
\hline
\end{tabular}

Sumber: Pengolahan Data SPSS

Pada tabel hasil uji reliabilitas (150 orang) memperlihatkan bahwa nilai cronbach's alpha dari self-disclosure 0,773 > 0,6, kepribadian extraversion 0,674 > 0,6 dan keterampilan komunikasi interpersonal $0,820>0,6$. Maka ketiga variabel ini dapat dinyatakan reliabel dan layak digunakan.

Tabel 3. Uji T

\begin{tabular}{|c|c|c|c|c|c|}
\hline \multirow{2}{*}{ Model } & \multicolumn{2}{|c|}{$\begin{array}{l}\text { Unstandardized } \\
\text { Coefficients }\end{array}$} & $\begin{array}{l}\text { Standardize } \\
\mathrm{d} \\
\text { Coefficient } \\
\mathrm{S}\end{array}$ & \multirow{2}{*}{$\mathrm{T}$} & \multirow{2}{*}{ Sig. } \\
\hline & B & $\begin{array}{l}\text { Std. } \\
\text { Error }\end{array}$ & Beta & & \\
\hline 1 (Constant) & 11.819 & 2.961 & & 3.992 & .000 \\
\hline Self-disclosure $\left(\mathrm{X}_{1}\right)$ & .282 & .087 & .261 & 3.226 & .002 \\
\hline $\begin{array}{l}\text { Kepribadian } \\
\text { Extraversion }\left(\mathrm{X}_{2}\right)\end{array}$ & .555 & .110 & .410 & 5.057 & .000 \\
\hline
\end{tabular}

Sumber: Pengolahan Data SPSS

Melalui hasil penelitian diketahui bahwa nilai sig untuk pengaruh variabel (X1) Self-disclosure terhadap Keterampilan Komunikasi Interpersonal adalah sebesar $0,002<0,05$. Sehingga dapat disimpulkan bahwa Self-disclosure memberikan 
Michael Roesyanto, Rezi Erdiansyah: Perngaruh Hubungan Self-Disclosure dan Kepribadian Extraversion terhadap Keterampilan Komunikasi Interpersonal Young Worker di Jakarta

pengaruh pada Keterampilan Young Worker untuk melakukan proses Komunikasi Interpersonal.

Selain itu, nilai sig untuk pengaruh (X2) Kepribadian Extraversion terhadap Keterampilan Komunikasi Interpersonal adalah sebesar 0,000. Maka 0,000<0,05, sehingga dapat disimpulkan bahwa Kepribadian Extraversion berpengaruh secara signifikan terhadap Keterampilan Komunikasi Interpersonal.

\section{Simpulan}

Peneliti mendapatkan kesimpulan dari 150 jawaban yang diberikan oleh responden bahwa:

1. Self-disclosure berpengaruh secara signifikan terhadap Keterampilan Komunikasi Interpersonal Young Worker di Jakarta dengan temuan dimensi tertinggi "mampu terbuka dalam kondisi apapun".

2. Kepribadian Extraversion juga berpengaruh secara signifikan terhadap Keterampilan Komunikasi Interpersonal Young Worker di Jakarta dengan temuan dimensi tertinggi "antusias dalam melakukan sebuah menghadapi sebuah hal".

3. Self-disclosure atau keterbukaan diri menjadi salah satu variabel yang berpengaruh namun apabila dibandingkan dengan variabel kepribadian extraversion, maka self-disclosure mempunyai nilai yang lebih rendah

4. Hasil kesimpulan tersebut didukung oleh teori yang mengatakan bahwa semakin tinggi tingkat kenyamanan dan kepribadian suka berteman maka akan semakin tinggi juga keterampilan komunikasi yang didapatkan.

\section{Ucapan Terima Kasih}

Sebagai akhir dari penelitian, peneliti ingin menyapaikan kepada pihak-pihak yang telah membatu, memberikan dukungan serta doa selama berlangsungnya proses penelitian ini terima kasih yang sebesar-besarnya.

\section{Daftar Pustaka}

Dr. Wahidmurni, M. (2017). Pemaparan Metode Penelitian Kuantitatif. Malang: Universitas Islam Negeri Maulana Malik Ibrahim Malang.

Erdiansyah, K. J. (2019). Pengaruh Konsep Diri dan Self-disclosure terhadap Kemampuan Komunikasi Interpersonal Mahasiswa. Jakarta: Universitas Tarumanagara.

Fraenkel, J. N. (2008). How to Design and Evaluate Research in Education. New York: McGraw-Hill Higher Education.

Hasan, M. I. (2002). Pokok-pokok Materi Metodologi Penelitian dan Aplikasinya. Bogor: Ghalia Indonesia.

Imaroh, H. I. (2017). Penanganan Pelayayanan Pengaduan Pelanggan Mengenai Keluhan Tidak Dapat Air (TDA) di PDAM Surya Sembada Surabaya. Surabaya: Universitas 17 Agustus 1945.

Mulyana, D. (2011). Ilmu Komunikasi. Bandung: PT. Rosdakarya.

Rabiah Rizki Siregar, Y. T. (2019). Kontribusi Kepribadian Big Five Terhadap Komunikasi Interpersonal Pada Mahasiswa Rantau Tahun Pertama. Padang: Universitas Negeri Padang. 
Sugiyono. (2015). Metode Penelitian Kuantitatif, Kualitatif dan R\&D. Bandung: Alfabeta.

Zulfa, N. I. (2019). Pengaruh Kompetensi Kepribadian dan Kompetensi Profesional Guru BK Terhadap Keterbukaan Diri Siswa Kelas VII dan IX di SMP Negeri Se-Kabupaten Patu Tahun Ajaran 2018/2019. Palembang: Universitas Negeri Semarang. 